\title{
Skeletal Muscle Metastases in Carcinoma Hypo Pharynx - a Rare Occurrence
}

\author{
Virmani Swati ${ }^{1 *}$, Pandey Manish ${ }^{1}$, Nagpal Puneet ${ }^{1}$, Pruthi Deep S ${ }^{1}$, Rewri Shivani ${ }^{2}$ and Agarwal Naveen $^{2}$ \\ ${ }^{1}$ Department of Radiation Oncology, Action Cancer Hospital, New Delhi, India \\ ${ }^{2}$ Department of Oncopathology, Action Cancer Hospital, New Delhi, India
}

Submission: June 26, 2021; Published: July 09, 2021

*Corresponding author: Dr. Swati Virmani, Department of Radiation Oncology, Action Cancer Hospital, New Delhi, India

\begin{abstract}
Skeletal muscle metastases from hypo pharynx cancer are a very rare finding. The most common metastases in hypo pharynx cancer are seen to lungs, bones and liver. However, here we present a rare case of carcinoma hypopharynx with skeletal metastases to rectus abdominis muscle. Patient was a documented case of multiple metastases to bone, adrenals and skeletal muscle as per whole body PET-CT scan. Skeletal muscle metastases are rare and has no specific pattern of occurrence. Skeletal muscle metastases should always be considered as differential diagnosis for soft tissue sarcoma therefore, such patients should be looked with suspicion and needle biopsy is mandatory for final diagnosis.
\end{abstract}

\section{Introduction}

Hypo pharyngeal and oral pharyngeal cancers constitute about $1.1 \%$ of all the malignancies in the world and about $3.8 \%$ of all malignancies in India [1]. The order of distant metastases in carcinoma hypo pharynx is the lungs $(60 \%)$, followed by bones $(20 \%)$, and liver (common in autopsy studies but clinical liver metastases develop in only $10 \%$ of the patients) [2]. Distant metastases to the skeletal muscle are extremely rare. Skeletal muscle metastasis is a rare phenomenon with reported incidence of approximately $0.16-0.03 \%$ in clinical practice and $0.8 \%$ in autopsy study [3]. The most common malignancies that metastasize to skeletal muscle are lung cancer $(25 \%)$, gastrointestinal tumors (21\%), urological tumors (13\%), genital tumors (9.3\%) and breast cancer (8.2\%) [4]. The most common anatomical site of muscle metastases are lower limbs followed by chest wall and paravertebral musculature [5]. We report here a case of a patient with skeletal muscle metastases as the initial presentation in a case of metastatic carcinoma hypo pharynx.

\section{Case Report}

A 56-year-old male who was chronic smoker and an alcoholic with no known comorbidities presented with difficulty in swallowing and swelling over the right side of the neck for four months before coming to the clinician in September'2020.He also had hoarseness of voice, loss of appetite and abdominal pain for the same duration. Fine needle aspiration cytology from cervical swelling (17/09/2020) suggestive of metastatic squamous cell carcinoma. Biopsy from pyriform sinus (19/09/2020) suggestive of poorly differentiated squamous cell carcinoma. Patient took alternative treatment for two months (details of which are unknown) and did not consult any oncologist. Patient presented to Action cancer Hospital in December 2020 with difficulty in swallowing for solids as well as liquids and increase in size of swelling over right side of neck. Patient underwent a wholebody positron emission tomography (PET) scan (29/12/2020) which revealed $2.9 \times 2.6 \mathrm{~cm}$ ulcerative soft tissue density mass involving right aryepiglottic fold, pyriform sinus and adjoining posterior pharyngeal wall. Cystic lymph-node with irregular wall thickening is seen in right cervical level III region $(3.5 \mathrm{X} 3.4 \mathrm{~cm})$. Other discrete lymph nodes are seen in right cervical level II, III and left cervical level $\mathrm{II}(1.1 \mathrm{x} 1 \mathrm{~cm})$. Another small lymph-node is seen in right para pharyngeal space. Ill-defined nodular lesion Is seen involving left adrenal.

Nodular lesion, measuring $2.1 \mathrm{X} 1.4 \mathrm{~cm}$ is seen involving right lower rectus. Lytic lesions are seen involving bilateral $10^{\text {th }}$ and left $9^{\text {th }}$ ribs, L2 and L5 vertebrae, right iliac bone. Soft tissue component is seen with left $9^{\text {th }}$ rib lesion (Figure 1). Patient was diagnosed as squamous cell carcinoma hypo pharynx (stage IV).CT Guided biopsy from right rectus abdominis nodule (02/01/2021) 


\section{Cancer Therapy \& Oncology International Journal}

suggestive of Metastatic deposit of squamous cell carcinoma and immunohistochemistry (CK5/6 positive and p40 positive) confirmed its primary to be the same (Figure 2). He received one cycle of three weekly Paclitaxel, carboplatin and cetuximab based chemotherapy till 12/02/2021. However, he complained of lower Backache and pain in right hip. Patient was then referred to radiation oncology department for opinion. We planned external beam radiotherapy to lumbosacral spine and right iliac bone using 15 mega volt (MV) photon beams on linear accelerator (Clinac iX Linear accelerator) to a dose of 30 Gy in 10 fractions (Daily once, 5 days a week). Thereafter, patient complained of burning micturition and pain during micturition. Ultrasound KUB with post void residual urine test was done (26/02/2021) which revealed left kidney measuring 12.8 X6.3 cm, appears mildly bulky with mild hydronephrosis. Post void residue and measures 110 cc(significant). He underwent cystoscopy, Left DJ stenting under spinal anaesthesia on 03/03/2021.Thereafter, patient continued three weekly Paclitaxel, carboplatin and cetuximab based chemotherapy and received four cycles of chemotherapy till 29/04/2021. Patient lost to follow up after that due to COVID-19 pandemic.
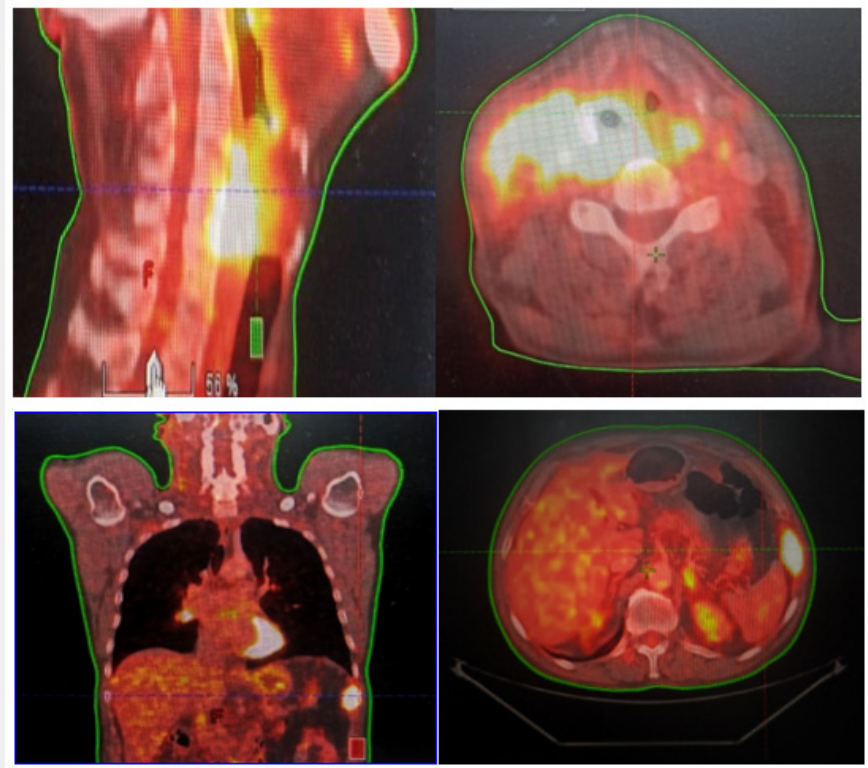

Figure 1: PET-CT image of hypopharynx

a. Ulcerative soft tissue density mass involving right aryepiglottic fold, pyriform sinus and adjoining posterior pharyngeal wall. b. $\quad$ Nodular lesion, measuring $2.1 \times 1.4 \mathrm{~cm}$ is seen involving right lower rectus.
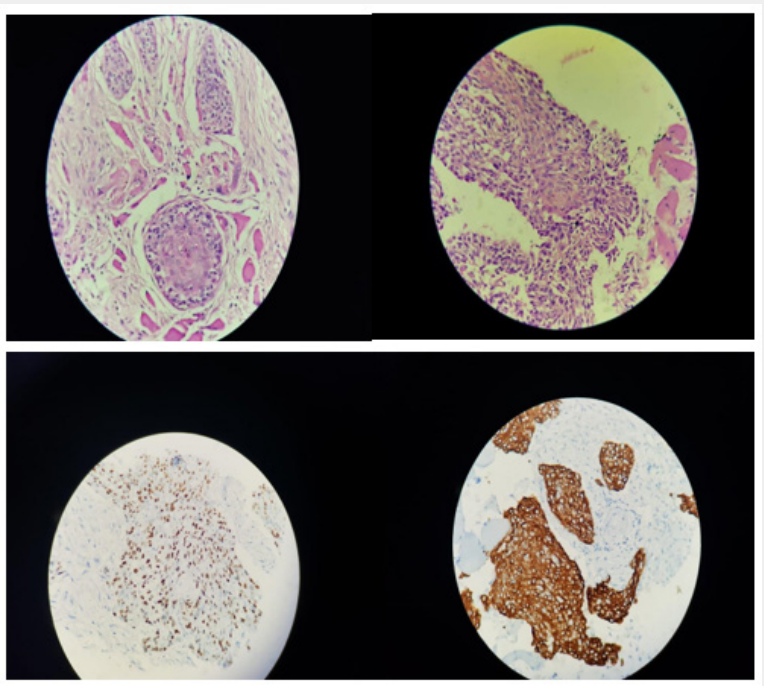

Figure 2: Microscopic appearance of the metastatic hypopharynx in the rectus abdominis muscle

a. H\&E staining shows a tumor infiltating skeletal muscle fibre. Tumor is present in nodules and in trabeculae composed of cells with moderate eosinophilic to few with vacuolated cytoplam. Individual cell keratinization observed.

b. Positive immunohisochemistry for $\mathrm{p} 40$ and CK5/6. 


\section{Cancer Therapy \& Oncology International Journal}

\section{Discussion}

Skeletal muscle metastases from hypo pharynx cancer are a very rare finding. There are only limited case reports in the literature regarding their incidence. The most common metastases in hypo pharynx cancer are seen to lungs, bones and liver. Although skeletal muscles constitute nearly half of the total human body mass and are well vascularized, metastases to the musculature are rare. Although the reasons for rarity are not well established, some factors that might contribute for the infrequency of skeletal muscle metastases have been postulated. First, skeletal muscle might present as a difficult site for implantation and growth of tumour cells due to inconstant blood flow and changing tissue pressure caused by muscle contraction. Second, there is the release of lactic acid into skeletal muscle creating an acidic environment, inhibiting tumour cell proliferation. Third, presence of natural killer cells and/or lymphocytes in the skeletal muscle which play a major role in the inhibition of tumour metastases $[6,7]$.

Skeletal muscle metastases generally present as "painful mass", but it may also be an incidental finding in imaging studies in asymptomatic patients [8]. Sometimes, as in our case, it can be the initial presentation of undiagnosed primary tumour with or without other distant metastases. Multiple imaging modalities, including computed tomography (CT), magnetic resonance imaging (MRI) have been used to evaluate and define the extent of tumour in skeletal muscle and its relationship to adjacent bone, facial planes, vessels and fat. However, it is difficult to differentiate intramuscular metastasis and primary soft tissue sarcoma, hence needle biopsy is mandatory for final diagnosis [8].

In a retrospective series by Yilihamu Tuoheti between January 1994 to October 2003, a total number of 12 patients were included in the study (10 male and 2 females with mean age of 68 years). The clinicopathological findings of all the patients with skeletal muscle metastases of carcinomas were reviewed. The cancers most frequently causing skeletal muscle metastases were lung $(33.3 \%)$, stomach $(16.6 \%)$, urinary bladder $(8.3 \%)$, thyroid $(8.3 \%)$, uterus $(8.3 \%)$ and gingiva $(8.3 \%)$. Seven patients had a mean survival of nine months after the detection of skeletal muscle metastasis while four patients were alive with a mean of 18.5 months after the radiation therapy. Only one patient was continuously disease free for 92 months after wide excision of the metastatic lesion [9].

Hung-ling Huang et al presented a case report of a 43-year-old male with recurrent hypo pharyngeal squamous cell carcinoma with initial cervical lymph-node involvement but only distant skeletal muscle metastases to the left quadriceps femoris muscle was noted. Patient underwent complete surgical excision of the mass and histopathology was compatible with the morphology of previous hypo pharyngeal cancer. He further received radiotherapy to the mass to a dose of 30 Gy in 10 fractions followed by three cycles of cisplatin and 5- fluorouracil-based chemotherapy. Patient was on follow-up for 16 months after the treatment and no obvious soft tissue metastatic lesion was noted in positron emission tomography (PET CT) [10].

The limited number of cases of skeletal muscle metastates from hypo pharyngeal cancer makes it difficult to determine the treatment of choice. Current recommendations for treatment of distant metastases from head and neck cancer include either systemic chemotherapy with cetuximab and platinum-based agents or enrollment into clinical trial [11]. The EXTREME (Erbitux in first line treatment of recurrent or metastatic head and neck cancer) study demonstrated that adding cetuximab to platinum-based chemotherapy significantly prolong the median overall survival from 7.4 months in chemotherapy alone group to 10.1 months in group that received cetuximab along with platinum-based chemotherapy [12].

\section{Conclusion}

Skeletal muscle metastases, as in our case, may be the initial presentation of undiagnosed metastatic hypo pharynx cancer with or without distant metastases. Skeletal muscle metastases should always be considered as differential diagnosis for soft tissue sarcoma, hence needle biopsy is mandatory for final diagnosis. The treatment for metastatic head and neck cancer includes either systemic chemotherapy or enrollment into clinical trial. Ultimately, with a diagnosis of skeletal muscle metastases, overall survival is poor and driven mainly by the treatment of primary carcinoma.

\section{References}

1. International agency for research on Cancer (2020) Globocan: 2020.

2. Garden AS, Morrison W H. Larynx and hypo pharynx cancer. In: Tepper JE, Foote RL, Michalski JM (Eds). Gunderson and Tepper's clinical radiation oncology. $5^{\text {th }}$ edn. Elsevier, Philadelphia, USA, pp. 679-703.

3. Weiss L (1989) Biomechanical destruction of cancer cells in skeletal muscle: a rate-regulator for hematogenous metastasis. Clin Exp Metastasis 7(5): 483-491.

4. Surov A, Kohler J, Wienke A, Gufler H, Bach AG, et al. (2014) Muscle metastases: comparison of features in different primary tumours. Cancer Imaging 14: 21.

5. T A Damron, J Heiner (2000) Distant soft tissue metastases: a series of 30 new patients and 91 cases from the literature. Ann Surg Oncol 7(7): 526-534.

6. Seely S (1980) Possible reasons for the high resistance of muscle to cancer. Med Hypotheses 6(2): 133-137.

7. Arpaci T, Ugurluer G, Akbas T, R B Arpaci, M Serin (2012) Imaging of the skeletal muscle metastases. Eur Rev Med Pharmacol Sci 16(15): 2057-2063.

8. Herring CL, Jr, Harrelson JM, Scully SP (1998) Metastatic carcinoma to skeletal muscle. A report of 15 patients. Clin Orthop Relat Res 355: 272-281.

9. Tuoheti Y, Okada K, Osanai T, Nishida J, Ehara S, et al. (2004) Skeletal muscle metastases of carcinoma: a clinicopathological study of 12 cases. Jpn J Clin Oncol 34(4): 210-214. 


\section{Cancer Therapy \& Oncology International Journal}

10. Huang HL, Hsu JF, Lin SF (2014) Recurrent local advanced hypopharyngeal squamous cell carcinoma with isolated quadriceps femoris metastases. Kaohsiung Journal of Medical sciences 30(11): 589-590.

11. NCCN Guidelines Version 1.2021. Head and Neck cancers. National Cancer Comprehensive Network.
12. Vermorken J B, Mesia R, Rivera F, Remenar E, Kawecki A, et al. (2008) Platinum-based chemotherapy plus cetuximab in head and neck cancer. The New England Journal of Medicine 359(11):1116-1127.
This work is licensed under Creative

Commons Attribution 4.0 License

DOI:10.19080/CTOIJ.2021.19.556008
Your next submission with Juniper Publishers will reach you the below assets

- Quality Editorial service

- Swift Peer Review

- Reprints availability

- E-prints Service

- Manuscript Podcast for convenient understanding

- Global attainment for your research

- Manuscript accessibility in different formats ( Pdf, E-pub, Full Text, Audio)

- Unceasing customer service

Track the below URL for one-step submission https://juniperpublishers.com/online-submission.php 